\title{
La revocación de actos dictados al amparo de normas tributarias no conformes al Derecho de la Unión Europea a la luz de las recientes reformas normativas
}

\author{
Juan Calvo Vérgez (España) \\ Universidad de Extremadura \\ jucaver@unex.es
}

\begin{abstract}
NOTA BIOGRÁFICA
Juan Calvo Vérgez es Profesor Titular de Universidad, contando con acreditación de ANECA a Catedrático de Universidad. Algunas de sus principales líneas de investigación son las relativas a la aplicación del principio de reserva de ley en materia tributaria, la financiación autonómica y local, el control presupuestario de los Entes públicos, el régimen fiscal de las entidades financieras o la recapitalización de las entidades bancarias, por citar las más relevantes.
\end{abstract}

\section{RESUMEN}

El presente trabajo tiene por objeto analizar el alcance del vigente art. 32 de la Ley 40/2015, de 1 de octubre, de Régimen Jurídico del Sector Público, encargado de regular de forma expresa la responsabilidad del Estado cuando los daños deriven de la aplicación de una norma con rango de ley declarada inconstitucional y cuando los daños deriven de la aplicación de una norma contraria al Derecho de la Unión Europea. Con carácter previo se analiza el proyectado art. 219 bis de la Ley 58/2003, de 17 de diciembre, General Tributaria, que finalmente no salió adelante.

\section{PALABRAS CLAVE}

Unión Europea; revocación; Ley General Tributaria; responsabilidad patrimonial del Estado Legislador; declaración de inconstitucionalidad.

\section{ABSTRACT}

The purpose of this paper is to analyze the scope of the current art. 32 of Law 40/2015, of October 1, on the Legal Regime of the Public Sector, in charge of expressly regulating the responsibility of the State when the damages derive from the application of a norm with the rank of a law declared unconstitutional and when the damages derive from the application of a rule contrary to European Union law. With prior carácter it is analyzed the projected art. 219 bis of Law 58/2003, of December 17, General Tax, which finally did not succeed.

\section{KEYWORDS}

European Union; revocation; General Tax Law; patrimonial liability of the Legislative State; declaration of unconstitutionality.

\section{SUMARIO}

I. ALCANCE DE LA REGULACIÓN CONTENIDA EN EL ANTEPROYECTO DE LEY DE REFORMA DE LA LGT. II. REFLEXIONES CRÍTICAS SOBRE LA REGULACIÓN INICIALMENTE PROYECTADA. III. LA ACTUAL REGULACIÓN CONTENIDA EN EL ART. 32 DE LA LEY 40/2015, DE 1 DE OCTUBRE, DE RÉGIMEN JURÍDICO DEL SECTOR PÚBLICO. IV. A MODO DE CONCLUSIÓN. 


\section{ALCANCE DE LA REGULACIÓN CONTENIDA EN EL ANTEPROYECTO DE LEY DE REFORMA DE LA LGT}

Como seguramente se recordará el Anteproyecto de Ley de Reforma de la Ley 58/2003, de 17 de diciembre, General Tributaria (LGT) redactado en su día preveía modifica los arts. 119 y 120 de la citada Ley 58/2003 con la finalidad de eliminar la posibilidad de solicitar una devolución mediante el denominado método de responsabilidad patrimonial del Estado por actos del poder legislativo en el ámbito tributario. De acuerdo con la citada regulación proyectada cuando, como consecuencia de una autoliquidación, se hubiesen aplicado normas tributarias declaradas inconstitucionales, ilegales o no conformes al derecho de la Unión Europea y se pretendiera exigir la responsabilidad patrimonial al legislador, el único procedimiento que podría instarse sería el de rectificación de autoliquidaciones, lo que limitaría la cantidad de años que se podrían exigir.

En efecto, la citada regulación proyectada preveía la modificación de los arts. 119 y 120 de la LGT para eliminar la posibilidad de solicitar una devolución mediante el citado método de la responsabilidad patrimonial del Estado por actos del poder legislativo en el ámbito tributario. De este modo si, a resultas de la práctica de una autoliquidación, se hubiesen aplicado normas tributarias declaradas inconstitucionales, ilegales o no conformes al ordenamiento comunitario y se pretendiera exigir la responsabilidad patrimonial al legislador, el único procedimiento que podría instarse sería el de rectificación de autoliquidaciones, lo que limita la cantidad de años que se pueden exigir.

De acuerdo con la regulación normativa diseñada por aquel entonces se incorporaba un nuevo apartado 4 en el art. 120 de la LGT, regulador de las «Autoliquidaciones», a través del cual se efectuaba una remisión al procedimiento establecido en el nuevo art. 219 bis 2 y 3 de la Ley, al objeto de poder llevar a cabo la rectificación de las autoliquidaciones efectuadas por los obligados en las que se hubiese aplicado normas tributarias declaradas no conformes al Derecho de la Unión Europea. Dicho apartado 4 incorporado al art. 120 de la LGT presentaba la siguiente redacción: "4. Cuando como consecuencia de una autoliquidación del obligado tributario en la que se hayan aplicado normas tributarias declaradas inconstitucionales, ilegales o no conformes al Derecho de la Unión Europea, se pretenda exigir responsabilidad patrimonial del Estado legislador, el único procedimiento que podrá instarse será el de rectificación de autoliquidaciones al que se refiere el apartado anterior, resultando de aplicación lo establecido en el artículo 219 bis. 2 y 3 de esta ley en lo relativo a los efectos temporales y prescripción.».

Ha de advertirse además que la citada reforma afectaría a los actos de la Administración tributaria posteriores al 1 de enero de 2015. En todo caso dicha regulación proyectada contemplaba las reclamaciones de responsabilidad patrimonial del Estado referidas a actos de la Administración tributaria no limitando el derecho a reclamar y otorgando una mayor seguridad jurídica a esas reclamaciones, ya fuesen por inconstitucionalidad o por infracción del Derecho Comunitario.

Con carácter adicional la citada regulación proyectaba introducir un nuevo y específico procedimiento de revocación de los actos dictados al amparo de normas tributarias declaradas no conformes al Derecho de la Unión Europea, disponiéndose a tal efecto la modificación de los arts. 213 y 216 de la LGT, así como la incorporación de un nuevo art. 219 bis y la introducción de un conjunto de normas complementarias de carácter transitorio recogidas en el número 6 de la Disposición Transitoria Única del Proyecto de Ley.

La modificación introducida en el art. 213 de la LGT presentaba un carácter meramente técnico. A través de su apartado segundo ${ }^{1}$ se incorporaba la posibilidad de que las resoluciones firmes de los órganos económico-administrativos y los actos de aplicación de los tributos y de imposición de sanciones sobre los que hubiera recaído una resolución económico-administrativa fuesen revisados en vía administrativa mediante la revocación de los actos dictados al amparo de normas declaradas inconstitucionales, ilegales o no conformes al Derecho de la Unión Europea del art. 219 bis de la Ley 58/2003. Esta posibilidad de revisión contemplada en el citado apartado 2 del art. 213 de la LGT resultaba respaldada además por la modificación de la letra d) del art. 216 de la Ley, la cual tenía por objeto la creación de un nuevo procedimiento especial de revisión de los relacionados en ese mismo art. 216 de la Ley referido a la «Revocación de los actos dictados al amparo de normas declaradas inconstitucionales, ilegales o no conformes al Derecho de la Unión Europea del art. 219 bis de la Ley».

1 Como es sabido este precepto alude a los denominados «Medios de revisión», integrados por el recurso de reposición y las reclamaciones económico administrativas. 
De este modo, a través de las modificaciones proyectadas de manera coordinada en los citados arts. 213.2 y 216 d) de la LGT se incorporaba a los denominados procedimientos especiales de revisión un nuevo procedimiento de revocación, recogido en la letra d) del art. 216 de la Ley y desarrollado en el art. 219 bis, cuyo título era el de «Revocación de actos dictados al amparo de normas tributarias declaradas inconstitucionales, ilegales o no conformes al Derecho de la Unión Europea». Se trataba, en líneas generales, de un nuevo procedimiento de revocación de carácter paralelo al regulado en el art. 219 de la Ley 58/2003, referente a la «revocación de actos de aplicación de los tributos y de imposición de sanciones».

El citado art. 219 bis, relativo a la revocación de actos dictados al amparo de normas tributarias declaradas inconstitucionales, ilegales o no conformes al Derecho de la Unión Europea, presentaba la siguiente redacción: «1. La Administración tributaria revocará sus actos en beneficio de los interesados cuando hubiesen sido dictados al amparo de normas tributarias declaradas inconstitucionales, ilegales o no conformes al Derecho de la Unión Europea. También se revocarán los actos sobre los que hubiera recaído resolución económico-administrativa.

La responsabilidad patrimonial del Estado legislador en materia tributaria que pudiera derivarse de la inconstitucionalidad, ilegalidad o no adecuación al Derecho de la Unión Europea de las normas tributarias, se determinará exclusivamente a través de este procedimiento, salvo lo establecido en el artículo 120.4 de esta ley.

2. La resolución que se dicte estará condicionada por los efectos retroactivos que se deriven de la sentencia que declare la inconstitucionalidad o la ilegalidad de la norma o su no conformidad con el Derecho de la Unión Europea.

Para la determinación de los efectos retroactivos se atenderá al contenido de la sentencia y, en el caso de que ésta no contenga pronunciamiento al respecto, a la doctrina de los tribunales en materia de inconstitucionalidad, ilegalidad o no adecuación de la norma al Derecho de la Unión Europea.

3. La revocación de los actos dictados al amparo de normas tributarias declaradas inconstitucionales, ilegales o no conformes al Derecho de la Unión Europea sólo será posible mientras no haya transcurrido el plazo de prescripción desde que se haya producido el último acto con facultad interruptiva de la misma dictado con anterioridad a la sentencia que hubiese declarado la inconstitucionalidad, ilegalidad o no conformidad al Derecho de la Unión Europea.

4. El procedimiento para declarar la revocación a que se refiere este artículo podrá iniciarse:

a) Por acuerdo del órgano que dictó el acto o de su superior jerárquico.

b) A instancia del interesado.

Será competente para declararla el órgano que se determine reglamentariamente, que deberá ser distinto del órgano que dictó el acto.

En el expediente se dará audiencia a los interesados. En todo caso deberá emitirse informe por el órgano con funciones de asesoramiento jurídico, que podrá tener carácter individual o genérico, sobre la procedencia de la revocación. Cuando se pretenda la revocación de actos confirmados por resoluciones económico-administrativas, se solicitará informe al Tribunal que dictó la resolución.

5. El plazo máximo para notificar resolución expresa será de seis meses desde la notificación del acuerdo de iniciación del procedimiento.

Transcurrido el plazo establecido en el párrafo anterior sin que se hubiera notificado resolución expresa, se producirán los siguientes efectos:

a) Si el procedimiento se hubiese iniciado de oficio se producirá la caducidad del mismo, sin que ello impida que pueda iniciarse de nuevo otro procedimiento con posterioridad.

b) Si el procedimiento se hubiera iniciado a instancia del interesado se considerará desestimada la solicitud por silencio administrativo.

6. La resolución expresa o presunta o el acuerdo de inadmisión a trámite de las solicitudes de los interesados pondrán fin a la vía administrativa.».

Como fácilmente puede colegirse, el art. 219 bis de la LGT a través del cual se creaba este nuevo procedimiento de revocación susceptible de iniciarse a instancia del interesado en el caso de actos basados en ilícitos comunitarios constaba de seis apartados. El primero de ellos regulaba el objeto de la revocación, previéndose en el mismo la posibilidad de que la Administración tributaria revocara sus propios actos en beneficio de los interesados cuando hubiesen sido dictados al amparo de normas tributarias declaradas inconstitucionales, ilegales o no conformes al Derecho de la Unión Europea. Con carácter adicional se revocarían los actos sobre los que hubiera recaído resolución económico-administrativa. 
Ahora bien ya en el art. 219 de la Ley se establecía la posibilidad de instar la revocación de los actos administrativos que infringen manifiestamente la Ley. Y, tal y como ha precisado MENÉNDEZ MORENO², mediante la adopción de un criterio de interpretación extensivo cabría la posibilidad de estimar que estos actos revocables al amparo de lo dispuesto en el art. 219 de la Ley comprendiesen también los supuestos a que se refiere el objeto de revocación del nuevo procedimiento del art. 219 bis.

A diferencia de lo que sucede en el art. 219.2 de la LGT nada se señalaba en el citado art. 219.bis proyectado acerca de la prohibición de que la revocación pudiera constituir dispensa o exención no permitida por las normas tributarias o ser contraria al principio de igualdad, al interés público o al ordenamiento jurídico. Cabía estimar, en consecuencia, que los supuestos que constituían el objeto de revocación del art. 219 bis no tenían estos límites que contemplaba el párrafo segundo del art. 219.1 de la Ley, los cuales se aplican únicamente en el procedimiento general de revocación. En consecuencia dichos supuestos podrían ser revocados en todo caso ya que, por su propia naturaleza, no pueden constituir ninguna de las situaciones que se acaban de mencionar de dispensa, exención o vulneración de la igualdad, el interés público o el ordenamiento. La ausencia de toda regulación al respecto parecía que podía ser interpretada como un motivo expreso de exclusión de la prohibición de revocación si concurrieran tales supuestos.

No obstante, dado que tanto el procedimiento del art. 219 como el regulado en el art. 219.bis son instruidos en beneficio de los interesados, podrían revocarse aquellos actos de gravamen que recayesen sobre esos interesados así como sobre que la Administración someta revisión, ya se tratase de actos y resoluciones económico-administrativas que resultasen firmes como si no lo fuesen, sin perjuicio del límite de los efectos temporales y del plazo de prescripción establecido al efecto.

El proyectado art. 219.bis.1 de la LGT regulaba las consecuencias o el alcance del procedimiento de revocación en él contemplado, precisando a tal efecto que la responsabilidad patrimonial del Estado legislador en materia tributaria que pudiera derivarse de los tres supuestos que constituyen su objeto (la inconstitucionalidad, la ilegalidad o la no adecuación al Derecho de la UE de las normas tributarias), se determinaría exclusivamente a través de este procedimiento, salvo lo establecido en el art. 120.4 de la Ley. Así las cosas cuando en el procedimiento de rectificación de las autoliquidaciones previsto en art. 120.3 de la Ley los obligados tributarios hubiesen aplicado normas tributarias declaradas inconstitucionales, ilegales o no conformes al Derecho de la UE y pretendieran exigir responsabilidad patrimonial del Estado legislador resultaría de aplicación lo establecido en el art. 219 bis. 2 y 3 de la LGT en lo relativo a los efectos temporales y prescripción.

El apartado segundo del proyectado art. 219 bis de la LGT se remitía, para la determinación de los efectos retroactivos que pudieran derivarse de la sentencia en cuestión, en ausencia de pronunciamiento al respecto, a la doctrina de los tribunales en materia de inconstitucionalidad, ilegalidad o no adecuación de la norma al Derecho de la Unión Europea.

Respecto de los efectos retroactivos de la resolución del procedimiento de revocación el proyectado art. 219 bis disponía que dichos efectos quedarían condicionados por los que se derivasen de la sentencia que declarara la inconstitucionalidad o la ilegalidad de la norma o de su no conformidad con el Derecho de la Unión Europea. Y, en cuanto a la determinación de los efectos retroactivos de las sentencias, el segundo párrafo del citado art. 219.bis manifestaba que si en las referidas sentencias no se hiciera pronunciamiento al respecto se atendería a la doctrina de los tribunales en materia de inconstitucionalidad, ilegalidad o no adecuación de la norma al Derecho de la Unión Europea. Coincidimos en este punto con MENÉNDEZ MO$\mathrm{RENO}^{3}$ cuando afirma que se trataba de un supuesto de norma en blanco que dejaba en gran medida sin determinar un aspecto tan relevante como el de los efectos retroactivos de la resolución del procedimiento de revocación del proyectado art. 219 bis.

Por su parte el apartado 3 de este art. 219.bis de la LGT proyectado se refería a la posibilidad de interponer el recurso de revocación en él contemplado, señalando al respecto que el mismo solo se podría interponer mientras no hubiese transcurrido el plazo de prescripción desde que se hubiera producido el último acto con facultad interruptiva de la misma dictado con anterioridad a la sentencia que hubiese declarado la inconstitucionalidad, ilegalidad o no conformidad al Derecho de la Unión Europea. El citado apartado 3 del precepto

\footnotetext{
2 MENÉNDEZ MORENO, A. (2014): “La proyección del Derecho de la Unión Europea en la reforma de la Ley General Tributaria. Especial referencia al nuevo procedimiento de revocación de los actos dictados al amparo de normas tributarias no conformes al Derecho de la Unión Europea", en Quincena Fiscal, núm. 17 (consultado en www.aranzadidigital.es).

${ }^{3}$ MENÉNDEZ MORENO, A. (2014): "La proyección del Derecho de la Unión Europea en la reforma de la Ley General Tributaria. Especial referencia al nuevo procedimiento de revocación de los actos dictados al amparo de normas tributarias no conformes al Derecho de la Unión Europea", ob. cit. (consultado en www.aranzadidigital.es).
} 
proyectado limitaba automáticamente los efectos ex tunc de la sentencia que hubiese declarado la inconstitucionalidad, la ilegalidad o no conformidad al Derecho de la Unión Europea al plazo de prescripción incluso en el supuesto de que el propio Tribunal Constitucional o el propio TJUE admitiesen dichos efectos ex tunc de la sentencia, desconociendo a tal efecto la competencia exclusiva que ostenta nuestro Tribunal Constitucional para interpretar la Constitución y la determinación de sus efectos ${ }^{4}$. Y es que, mientras que la firmeza de los actos y de las resoluciones económico-administrativas no impide la posibilidad de su revocación, el transcurso del plazo de prescripción -calculado conforme al criterio que se recogía en el artículo 219.bis.3- sí que hace imposible la revocación. Este mismo criterio se encuentra recogido en el apartado 2 del art. 219 de la LGT, de conformidad con el cual la revocación sólo será posible mientras no haya transcurrido el plazo de prescripción. En efecto, aun siendo posible revocar los actos firmes, no pueden revocarse los prescritos. Ahora bien debe precisarse que el citado art. 219.2 de la Ley 58/2003 no hace referencia alguna a la forma de computar el plazo de prescripción, al que sí aludía, como se ha señalado, el proyectado art. 219 bis de la LGT.

A la iniciación del procedimiento para declarar la revocación se refería el apartado 4 del proyectado art. 219 bis, previéndose a tal efecto la posibilidad de que esa iniciación se produjese por acuerdo del órgano que dictó el acto o de su superior jerárquico y también «a instancia del interesado». Esta doble posibilidad de iniciar el procedimiento proyectado representaba una novedad respecto del contenido del art. 219.3 de la LGT, a cuyo tenor el procedimiento de revocación se iniciará siempre de oficio. El citado apartado 4 del art. 219 bis se encargaba de regular la tramitación del nuevo procedimiento, disponiéndose al respecto que en el expediente se daría audiencia a los interesados, debiendo emitirse informe por el órgano en funciones de asesoramiento jurídico, que podría ser individual o genérico, sobre la procedencia de la revocación. Se trataba por tanto de un conjunto de apreciaciones que ya figuraban recogidas en el art. 219 de la Ley 58/2003. Ahora bien, como novedad el proyectado art. 219 bis.4 de la LGT añadía que cuando se pretendiese la revocación de actos confirmados por resoluciones económico-administrativas se solicitaría informe al Tribunal que dictó resolución. Como es lógico en estos supuestos habría de otorgarse audiencia al interesado, al tratarse de un procedimiento iniciado de oficio y que tendría como fundamento evitar la indefensión de los interesados. El hecho de que hubiera de contarse además con el informe del órgano asesor garantizaba la legalidad del procedimiento. Dicho informe no tendría carácter vinculante, si bien habría de motivar la resolución que hubiera de dictarse, evitando con ello la sospecha de arbitrariedad del órgano decisor.

El apartado 5 de este art. 219.bis de la LGT establecía el plazo de resolución expresa, que sería de seis meses, en sintonía con el plazo general de las actuaciones de la Administración en el ámbito tributario regulado en el art. 104.1 de la LGT. El cómputo de dicho plazo se iniciaría desde la notificación del acuerdo de iniciación del procedimiento, previéndose también los efectos del transcurso del mismo sin que se hubiera notificado resolución expresa. A tenor de dichos efectos, habiéndose el procedimiento de oficio se produciría la caducidad del mismo, sin que ello impidiese que pudiera iniciarse de nuevo otro procedimiento con posterioridad. Y si el procedimiento se hubiera iniciado a instancia del interesado se consideraría desestimada la solicitud por silencio administrativo.

Recuérdese a este respecto que en el procedimiento de revocación que regula el art. 219 de la Ley $58 / 2003$ se prevé únicamente la caducidad del procedimiento en aquellos casos en los que no se produzca su resolución expresa. Y ello en tanto en cuanto nada se dispone en el mismo acerca de la posibilidad de que el procedimiento pueda iniciarse a instancia del interesado, al no hallarse recogida dicha posibilidad. Debido a ello tampoco cabe la desestimación por silencio negativo, consecuencia lógica de lo anterior, al igual que sucede con la posibilidad de iniciar un nuevo procedimiento después de su caducidad, que tampoco resulta completada en el art. 219.

Finalmente señalaba el apartado 6 del proyectado art. 219.bis de la LGT que la resolución expresa o presunta o el acuerdo de inadmisión a trámite de las solicitudes de los interesados pondría fin a la vía administrativa. Por su parte el art. 219 de la LGT no contiene a este respecto referencia alguna a la inadmisión de las solicitudes de los interesados las cuales, insistimos, no se hallan previstas. Tal y como señala MENÉNDEZ MORENO ${ }^{5}$, dado el carácter especial de los procedimientos de revocación, parece razonable que no exista más que una instancia administrativa que sustancie y resuelva esta clase de procedimientos.

\footnotetext{
${ }^{4}$ Como es sabido el art. 267 del Tratado de Funcionamiento de la Unión Europea (TFUE) dispone que el TJUE es el único competente para determinar el alcance temporal de sus sentencias, estableciéndose, como regla general, los efectos ex tunc.

${ }^{5}$ MENÉNDEZ MORENO, A. (2014): "La proyección del Derecho de la Unión Europea en la reforma de la Ley General Tributaria. Especial referencia al nuevo procedimiento de revocación de los actos dictados al amparo de normas tributarias no conformes al Derecho de la Unión Europea", ob. cit. (consultado en www.aranzadidigital.es).
} 
Por otra parte a este procedimiento especial de revocación regulado en el proyectado art. 219.bis de la LGT le serían de aplicación las normas comunes del Capítulo I del Título V de la LGT (relativo a la «Revisión en vía administrativa»), comprensivo de los arts. 213 a 215, ambos inclusive. A resultas de la aprobación de este procedimiento se había previsto la derogación del procedimiento de anulación contra las resoluciones de los tribunales económico-administrativos, el cual se regulaba en el apartado 6 del art. 239 de la LGT.

La reforma proyectada debía afectar a los actos de la Administración tributaria posteriores al 1 de enero de 2015. A este respecto la Disposición Transitoria Única del Proyecto de Ley de reforma de la LGT preveía, en su número 6, que lo contemplado en el art. 219 bis (así como en los arts. 213.2 y 216 de la Ley 58/2003) resultara de aplicación en relación con las normas cuya declaración de inconstitucionalidad, ilegalidad o no conformidad al Derecho de la Unión Europea se produjese a partir de la entrada en vigor de la misma, al día siguiente de su publicación en el Boletín Oficial del Estado.

El apartado 6 de la citada Disposición Transitoria Única del Anteproyecto preveía por tanto que lo dispuesto en el art. 219 bis de la Ley 58/2003 fuese aplicable en relación con las normas cuya declaración de inconstitucionalidad, ilegalidad o no conformidad al Derecho de la Unión Europea se produjese a partir de la fecha de entrada en vigor de la Ley. No existía en consecuencia un régimen transitorio que permitiera a los interesados disponer de un plazo suficiente, después de la adopción de ésta, para poder presentar las solicitudes de responsabilidad patrimonial que pudieran interponer al amparo de la anterior normativa, viéndose por tanto afectadas acciones aún no entabladas en el momento de la entrada en vigor del nuevo plazo relativas a cantidades pagadas cuando el antiguo plazo era aplicable ${ }^{6}$.

De cualquier manera la regulación proyectada no limitaba sino que establecía un procedimiento específico y no el genérico previsto al efecto en la normativa administrativa aplicable. Se contemplaban así en la LGT las reclamaciones de responsabilidad patrimonial del Estado referidas a actos de la Administración tributaria. No se limitaba el derecho a reclamar, sino que se otorgaba mayor seguridad jurídica a esas reclamaciones, ya fuesen por inconstitucionalidad o por infracción del Derecho Comunitario, en opinión de la Administración tributaria.

En consecuencia de la redacción inicialmente proyectada se desprendía que en el procedimiento de revocación los interesados solamente podrían elevar una petición (en ejercicio del derecho que reconoce el art. 29 de la Constitución y que desarrolla el art. 10.1 del Real Decreto Real 520/2005, de 13 de mayo) dirigida al órgano administrativo que hubiese dictado el acto que se pretendiera revocar, la cual podría o no elevar al órgano reglamentariamente encargado de instruir y resolver el procedimiento que, de acuerdo con el art. 219.3 de la LGT, habría de ser distinto del órgano que dictó el acto, siendo además, a tenor de lo establecido en el art. 10.2 del RGRVA, el superior jerárquico del que lo hubiese dictado.

\section{REFLEXIONES CRÍTICAS SOBRE LA REGULACIÓN INICIALMENTE PROYECTADA}

Tal y como hemos tenido ocasión de analizar en el Epígrafe precedente de este trabajo en su día el Anteproyecto de Ley de reforma de la LGT introdujo un nuevo art. 219 bis denominado «revocación de actos dictados al amparo de normas tributarias declaradas inconstitucionales, ilegales o no conformes al Derecho de la Unión Europea» con la finalidad de regular un nuevo y único procedimiento en vía administrativa destinado a exigir la responsabilidad del Estado legislador en materia tributaria.

Con carácter adicional se añadía un nuevo apartado d) en el art. 216 de la LGT que incorporaba un nuevo supuesto de revocación de los actos dictados al amparo de las normas tributarias declaradas inconstitucionales, ilegales o contrarias al Derecho de la Unión Europea y de un apartado 4 en el art. 120 que esta-

\footnotetext{
6 Tal y como quedó reflejado en el Voto particular formulado por la Vocal Sra. Sáez Rodríguez, al Informe del Anteproyecto de la Ley de Modificación parcial de la Ley 58/2003 aprobado por el Pleno del Consejo General del Poder Judicial, en sesión celebrada el 30 de septiembre de 2014 el plazo general de un año que se pretendía eliminar «(...) Resulta esencial para interponer esta clase de reclamaciones y evitar la prescripción, dados los retrasos de los procedimientos judiciales, señaladamente los de inconstitucionalidad o los de disconformidad con el derecho de la UE. Con la eliminación de este plazo se evita o, al menos, se obstaculiza la declaración de responsabilidad patrimonial del Estado legislador vía prescripción de acciones en claro perjuicio para los ciudadanos». A través del citado Voto Particular venía así a señalarse que el Anteproyecto parecía confundir la revisión de actos administrativos con la responsabilidad patrimonial del legislador en la que no se pide la revisión de actos administrativos, sino la correspondiente responsabilidad patrimonial por la actuación contraria a Derecho de la Administración, en este caso por el uso de la potestad legislativa. En esta misma línea se situaría también el Informe del Consejo de Estado al referido Anteproyecto de dicha Ley (número de expediente 130/2015, de 9 de abril de 2015).
} 
blecía que cuando como consecuencia de una autoliquidación del obligado tributario en la que se hubiesen aplicado normas tributarias declaradas inconstitucionales, ilegales o no conformes al Derecho de la Unión Europea se pretendiera exigir responsabilidad patrimonial del Estado legislador el único procedimiento que podría instarse sería el de rectificación de autoliquidaciones.

De este modo tenía lugar la creación de un nuevo mecanismo especial de revisión cuya finalidad era la revocación de actos dictados al amparo de normas tributarias declaradas inconstitucionales, ilegales o no conformes al Derecho de la Unión Europea. El nuevo procedimiento creado al efecto suprimía ad futurum el derecho a instar la responsabilidad patrimonial del Estado para recuperar las cuotas tributarias satisfechas como consecuencia de liquidaciones o autoliquidaciones en las que se hubiesen aplicado normas tributarias declaradas inconstitucionales, ilegales o no conformes al Derecho de la Unión Europea. En efecto, a partir de la entrada en vigor de la citada modificación este nuevo procedimiento de revocación sería el único que podría instarse para recuperar esas cantidades indebidamente abonadas.

Tradicionalmente cuando una determinada norma tributaria es declarada inconstitucional, ilegal o contraria al Derecho de la Unión Europea el obligado tributario tiene -salvo que se hubieran limitado los efectos temporales de la sentencia- dos posibles alternativas. En primer lugar, si aún no hubiesen transcurrido los cuatro años de prescripción, instar un procedimiento de devolución de ingresos indebidos de esas cantidades. Y, en segundo término, en caso de hallarse prescrita dicha opción, recuperar las cuotas indebidamente ingresadas en aplicación de la norma declarada nula mediante el inicio de un procedimiento de responsabilidad patrimonial contra el Estado legislador. Pues bien a resultas de esta modificación proyectada, si bien se mantenía el procedimiento de devolución de ingresos indebidos para recuperar las cantidades abonadas en ejercicios no prescritos, se eliminaba la posibilidad de exigir la responsabilidad patrimonial del Estado legislador en el supuesto de prescripción, sustituyéndose dicha alternativa por el nuevo procedimiento de revocación de actos, cuyos requisitos y plazos temporales resultaban más exigentes y exiguos que los que la doctrina y la jurisprudencia venían exigiendo a la responsabilidad patrimonial del Estado legislador ${ }^{7}$.

$Y$ es que, mientras que al amparo de la regulación tradicionalmente aplicable el plazo para hacer efectiva dicha responsabilidad patrimonial es de un año a contar desde la firmeza de la sentencia que declarase la norma inconstitucional, ilegal o no conforme al Derecho de la Unión Europea, la posibilidad de acudir al nuevo procedimiento de revocación de actos proyectado al efecto sólo sería viable mientras no hubiese transcurrido el plazo de prescripción a contar desde que se hubiera producido el último acto con facultad interruptiva de la misma dictado con anterioridad a la sentencia. Significa ello que la posibilidad de recurrir a la revocación de actos únicamente constituiría una alternativa en tanto en cuanto entre la sentencia y el último acto del administrado tendente a discutir la legalidad de la norma que establece el impuesto no hubiesen mediado más de cuatro años. En otro caso se entendería prescrita la posibilidad de reclamar cualquier tipo de resarcimiento del Estado.

Por otra parte, y desde una perspectiva procedimental, la condición de órgano competente para la resolución del expediente recaía en la propia Administración tributaria, mientras que, como es sabido, el órgano competente para resolver la responsabilidad patrimonial del Estado legislador es el Consejo de Ministros. Tenía lugar por tanto la introducción de una variación en la competencia que, a nuestro juicio, podía terminar conduciendo a la práctica desaparición de las estimaciones en vía administrativa, ya que sería quien hubiese aplicado y recaudado el tributo quien, al menos en primera instancia, habría de reconocer la procedencia de su devolución.

En todo caso la aplicación de este mecanismo proyectado no resultaba inmediata ya que, de conformidad con lo establecido en el apartado 6 de la Disposición Transitoria Única del Anteproyecto de Ley de reforma de la LGT, la sustitución de la responsabilidad patrimonial del Estado legislador por el procedimiento de revocación de actos se produciría respecto de normas cuya declaración de inconstitucionalidad, ilegalidad o no conformidad al Derecho de la Unión Europea tuviese lugar a partir de la fecha de entrada en vigor de la modificación, lo que se produciría, al amparo de lo señalado en la Disposición Final Octava de dicho texto, al día siguiente de su publicación en el Boletín Oficial del Estado.

Ya en su día el Consejo de Estado, a través de su Dictamen núm. 130/2015, de 9 de abril de 2015, se encargó de precisar que desde un punto de vista lógico hubiera sido más procedente cambiar el orden de la rúbrica del proyectado art. 219.bis, al objeto de que el mismo aludiese a actos declarados ilegales, in-

7 Véase en este sentido FERNÁNDEZ-MIER GARCíA, J. (2014): "Responsabilidad patrimonial del Estado Legislador en el ámbito tributario", en Revista luris \& Lex, núm. 117, pág. 42. 
constitucionales o contrarios al Derecho de la Unión Europea. Opinaba además el Consejo de Estado en el citado Dictamen que «No debe incrustarse el régimen de la responsabilidad del Estado legislador entre los supuestos de revisión extraordinaria de actos administrativos firmes. Si bien en la práctica, la elección de una u otra vía puede llevar a similares consecuencias, no es del todo cierta esta "intercambiabilidad" en lo que hace a las exigencias formales, ni a las temporales, ni a los cauces a seguir (...) La revocación persigue corregir la ilegalidad y la responsabilidad del legislador atiende a la reparación de los perjuicios sufridos por esa ilegalidad». Téngase presente a este respecto que el citado precepto no parecía diferenciar con claridad entre la revisión de actos administrativos (y, en particular, el procedimiento de revocación), de una parte, y la responsabilidad patrimonial del Estado legislador, de otra.

Por otra parte puso de manifiesto el supremo órgano consultivo en el citado Dictamen que, por lo que respecta a los medios de iniciación del procedimiento, existía una contradicción entre la redacción del apartado 1 del art. 219 bis del Anteproyecto y el apartado 4 del citado precepto, a través del cual se permitía que el procedimiento se iniciase de oficio o a instancia del interesado, mientras que el apartado primero preveía únicamente el inicio de oficio de este procedimiento. A mayor abundamiento para el Consejo de Estado el art. 219.bis no preveía que la Administración pudiera revocar sus actos, sino que caracterizaba este supuesto como una «revisión debida», no contemplando la facultad de actuación de la Administración. Con carácter adicional el Consejo de Estado manifestó su disconformidad con el hecho de que el apartado 5 del art. 219 bis no estableciese el carácter preceptivo del informe del órgano con funciones de asesoramiento jurídico, a diferencia de lo que disponía el art. 142.3 de la Ley 30/1992, de 26 de noviembre, de Régimen Jurídico de las Administraciones Públicas y del Procedimiento Administrativo Común (actual art. 67 de la Ley 39/2015, de 1 de octubre, del Procedimiento Administrativo Común de las Administraciones Públicas).

Desde nuestro punto de vista una cuestión esencial de cara a garantizar el éxito de este procedimiento era que el interesado ostentara una verdadera acción o facultad de iniciar el procedimiento, de manera que no quedara la eficacia revisora del mismo condicionada, en último término, a la decisión final de la Administración. Y ello con independencia del necesario ejercicio de la acción de responsabilidad patrimonial del Estado Legislador en el plazo de un año a contar desde el momento en que se hubiese conocido la existencia del pronunciamiento comunitario que anulara el precepto en cuestión.

La regulación del procedimiento previsto al efecto en el citado art. 219.bis para depurar la responsabilidad patrimonial del Estado legislador en el ámbito tributario limitaba el plazo para solicitar la responsabilidad patrimonial, el cual quedaba circunscrito al plazo de prescripción desde que se hubiera producido el último acto con facultad interruptiva de la misma norma dictado con anterioridad a la sentencia que hubiese declarado la ilegalidad, inconstitucionalidad o no conformidad con el ordenamiento comunitario. A estos efectos la sentencia declaratoria de la inconstitucionalidad, ilegalidad o no conformidad con el Derecho de la Unión Europea carecía de efectos interruptivos ${ }^{8}$.

Ciertamente el apartado 1 del art. 219 bis LGT contenía una disminución de las situaciones revisables en relación con el régimen contenido en la Ley 39/2015, al excluir todos aquellos supuestos afectados por la cosa juzgada de la posibilidad de solicitar una indemnización derivada de la responsabilidad patrimonial del Estado legislador. La desestimación de la petición del interesado no podría ser recurrida, ya que el derecho de petición no es equivalente a una acción que pueda instar la iniciación del procedimiento. Su desestimación no tendría carácter resolutorio ni podría ser susceptible de recurso, ni en la vía administrativa ni en la jurisdiccional. Ahora bien en nuestra opinión la posibilidad de iniciación de oficio del procedimiento de revocación prevista en el proyectado art. 219.bis equivalía al reconocimiento de una acción en favor de los interesados, pudiendo la desestimación de esta última ser objeto de impugnación, al objeto de salvaguardar los derechos de los particulares.

Por otra parte, tanto en el procedimiento regulado en el art. 219 de la LGT como en el recogido en el proyectado art. 219.bis de la Ley se establecía que la competencia para declarar la revocación correspondería al órgano que se determinara reglamentariamente el cual, como es lógico, habría de ser distinto del órgano que hubiese dictado el acto.

8 Véase en este sentido PÉREZ BERNABEU, B. (2016): "La responsabilidad patrimonial del estado legislador en el ámbito tributario", en Quincena Fiscal, núm. 3 (consultado en www.aranzadidigital.es). A juicio de esta autora "La desaparición de este artículo 219 bis en el Proyecto de Ley de Reforma Parcial de la LGT es positiva, pues nunca llegamos a compartir los motivos que aducía el Anteproyecto en su Exposición de Motivos para justificar la regulación de un régimen jurídico específico que se apartara del que con carácter general se prevé en la normativa administrativa, pues ni consideramos que la complejidad ni especificidad ni la complejidad lo justifican, ni creemos que existiera una situación de vacío legal, a la vista de las distintas solicitudes de indemnización que, a lo largo de los años, se han ido instando y resolviendo bajo la normativa general». 
Recapitulando, con la finalidad de dotar al sistema tributario de una herramienta específica que permitiese recomponer la situación en aquellos supuestos en los que un acto de la Administración Tributaria deviene no conforme a Derecho como consecuencia de que la norma a la luz de la cual ha sido dictado hubiese sido declarada no conforme con el ordenamiento jurídico, ya fuese el interno (a través de una declaración de ilegalidad o inconstitucionalidad) o el ordenamiento de la Unión Europea (no conformidad con dicho ordenamiento), se establecía que se podría obtener la reparación del daño causado como consecuencia de dicho acto administrativo en aquellos supuestos en los que no pudiese operar la devolución de ingresos indebidos ordinaria por haber adquirido firmeza el acto administrativo en cuestión. Dicho mecanismo revocatorio pretendía sustituir, exclusivamente en el ámbito tributario, al procedimiento que en la actualidad, y con carácter general para el conjunto de los actos administrativos, se conforma a través de la responsabilidad patrimonial del Estado legislador. Ahora bien si resultase de aplicación el mecanismo de la prescripción no sería posible la revocación.

Por lo que respecta a aquellos supuestos en los que no existiese acto administrativo, esto es, a aquellos casos en los que el acto o actuación que se derivara de la aplicación de la norma declarada no conforme a Derecho no hubiese sido dictado por la Administración sino que hubiera sido materializado por el obligado tributario (piénsese, por ejemplo, en aquellos supuestos en los que se ha presentado una autoliquidación) se preveía la posibilidad de rectificar autoliquidaciones en el supuesto de que las mismas hubiesen sido presentadas al amparo de normas declaradas, de nuevo, ilegales, inconstitucionales o no conformes al Derecho de la Unión Europea.

Desde nuestro punto de vista a la luz de esta regulación proyectada cabía plantearse cómo entrarían a resolver los tribunales los eventuales recursos que pudieran llegar a plantearse sobre la legalidad de este procedimiento de revocación ya que, a la luz de la doctrina tradicional elaborada por nuestro Tribunal Supremo, todo acto de aplicación de una norma declarada inconstitucional, ilegal o no conforme al Derecho de la Unión Europea es nulo de pleno derecho y, en consecuencia, la acción para instar la declaración de nulidad de esos actos no podría ser sometida a un plazo en su ejercicio, no hallándose de este modo sujeta a prescripción. En cambio la regulación recogida en el Anteproyecto de Ley sometía a plazo el ejercicio de la acción de nulidad.

En suma, cabía plantearse hasta qué punto se introducían en la regulación de este nuevo procedimiento un conjunto de limitaciones cuestionables frente a las posibilidades de revisión que ya ofrece el procedimiento general de responsabilidad patrimonial del Estado Legislador. Finalmente el citado art. 219 bis terminó siendo retirado del texto definitivo del Proyecto de Ley de Reforma Parcial de la Ley General Tributaria146 que fue finalmente aprobado por Ley 34/2015, de 21 de septiembre.

\section{LA ACTUAL REGULACIÓN CONTENIDA EN EL ART. 32 DE LA LEY 40/2015, DE 1 DE OCTUBRE, DE RÉGIMEN JURÍDICO DEL SECTOR PÚBLICO}

En la actualidad es el art. 32 de la Ley 40/2015, de 1 de octubre, de Régimen Jurídico del Sector Público, el encargado de regular de forma expresa la responsabilidad del Estado cuando los daños deriven de la aplicación de una norma con rango de ley declarada inconstitucional y cuando los daños deriven de la aplicación de una norma contraria al Derecho de la Unión Europea. Con carácter general a través de la citada regulación se persigue igualmente restringir la extensión y amplitud con la que la jurisprudencia del Tribunal Supremo había interpretado la responsabilidad del Estado Legislador como consecuencia de Leyes declaradas inconstitucionales.

Señala concretamente este art. 32 de la Ley $40 / 2015$ en sus apartados 3 a $6^{9}$ lo siguiente: «3. Asimismo, los particulares tendrán derecho a ser indemnizados por las Administraciones Públicas de toda lesión que sufran en sus bienes y derechos como consecuencia de la aplicación de actos legislativos de naturaleza no expropiatoria de derechos que no tengan el deber jurídico de soportar cuando así se establezca en los propios actos legislativos y en los términos que en ellos se especifiquen.

La responsabilidad del Estado legislador podrá surgir también en los siguientes supuestos, siempre que concurran los requisitos previstos en los apartados anteriores:

\footnotetext{
9 Con carácter previo en sus dos primeros apartados se refiere este art. 32 de la Ley 40/2015 a la responsabilidad patrimonial de la Administración reconociendo el derecho de los particulares a acceder a una indemnización cuando sus bienes y derechos sufran algún detrimento que no tengan la obligación de soportar por el funcionamiento anormal o normal de la Administración, siempre y cuando el daño o perjuicio sea «efectivo, evaluable económicamente e individualizado» y resulte ajeno al ámbito de la fuerza mayor.
} 
a) Cuando los daños deriven de la aplicación de una norma con rango de ley declarada inconstitucional, siempre que concurran los requisitos del apartado 4.

b) Cuando los daños deriven de la aplicación de una norma contraria al Derecho de la Unión Europea, de acuerdo con lo dispuesto en el apartado 5.

4. Si la lesión es consecuencia de la aplicación de una norma con rango de ley declarada inconstitucional, procederá su indemnización cuando el particular haya obtenido, en cualquier instancia, sentencia firme desestimatoria de un recurso contra la actuación administrativa que ocasionó el daño, siempre que se hubiera alegado la inconstitucionalidad posteriormente declarada.

5. Si la lesión es consecuencia de la aplicación de una norma declarada contraria al Derecho de la Unión Europea, procederá su indemnización cuando el particular haya obtenido, en cualquier instancia, sentencia firme desestimatoria de un recurso contra la actuación administrativa que ocasionó el daño, siempre que se hubiera alegado la infracción del Derecho de la Unión Europea posteriormente declarada. Asimismo, deberán cumplirse todos los requisitos siguientes:

a) La norma ha de tener por objeto conferir derechos a los particulares.

b) El incumplimiento ha de estar suficientemente caracterizado.

c) Ha de existir una relación de causalidad directa entre el incumplimiento de la obligación impuesta a la Administración responsable por el Derecho de la Unión Europea y el daño sufrido por los particulares.

6. La sentencia que declare la inconstitucionalidad de la norma con rango de ley o declare el carácter de norma contraria al Derecho de la Unión Europea producirá efectos desde la fecha de su publicación en el "Boletín Oficial del Estado" o en el "Diario Oficial de la Unión Europea", según el caso, salvo que en ella se establezca otra cosa» ${ }^{10}$.

Adviértase por tanto como el número $3 .^{\circ}$ del art. 32 de la Ley 40/2015 regula la responsabilidad derivada de una actuación legítima y legal de la Administración por aplicación de normas no expropiatorias de derechos que generen un perjuicio que los particulares no tengan el deber jurídico de soportar, quedando condicionado el derecho a la indemnización por los propios actos legislativos que ocasionan el perjuicio lo reconozcan. En efecto, se limita el derecho a la reparación a que el legislador reconozca el derecho a la indemnización dentro de la misma norma que genera el perjuicio. No obstante, y tal y como precisa CAMPOS MARTÍNEZ ${ }^{11}$, el párrafo segundo del citado precepto plantea una responsabilidad patrimonial del EstadoLegislador relativa a aquellos supuestos cuya responsabilidad se origina de la declaración de ilegalidad, antijuridicidad o ilegitimidad de la norma, a saber, la responsabilidad por los daños derivados de la aplicación de una norma con rango de ley declarada inconstitucional y la responsabilidad por los daños derivados de la aplicación de una norma contraria al Derecho de la Unión Europea.

Por su parte el número $4 .^{\circ}$ del citado art. 32 de la Ley 40/2015 delimita un nuevo requisito exigido para que el particular pueda acceder a la indemnización cuando el daño se produzca de la declaración de inconstitucionalidad de la norma, como es el relativo a la obtención, en cualquier instancia, de sentencia firme desestimatoria en un recurso contra la actuación administrativa que ocasionó el daño, siempre que se hubiera alegado la inconstitucionalidad posteriormente declarada. Ahora bien a tenor de lo señalado por el art. 34 de la citada Ley la indemnización sólo resultará posible si la sentencia de que se trate hubiese sido dictada dentro de los cinco años anteriores a la declaración de inconstitucionalidad ${ }^{12}$. Se limitan pues los efectos temporales a los cinco años anteriores a la fecha de la publicación de la sentencia, previéndose además que,

10 Añade además el número $8 .^{\circ}$ de este precepto que el Consejo de Ministros fijará el importe de las indemnizaciones que proceda abonar cuando el Tribunal Constitucional haya declarado, a instancia de parte interesada, la existencia de un funcionamiento anormal en la tramitación de los recursos de amparo o de las cuestiones de inconstitucionalidad. Y el número $9 .^{\circ}$ de dicho precepto establece que el procedimiento a seguir en estos supuestos será el previsto en la Ley de Procedimiento Administrativo Común de las Administraciones Públicas sin perjuicio de las especialidades que, en su caso, estableciese el antiguo Real Decreto Legislativo $3 / 2011$, de 14 de noviembre, por el que se aprobaba el Texto Refundido de la Ley de Contratos del Sector Público (actual Ley 9/2017, de 8 de noviembre, de Contratos del Sector Público).

11 CAMPOS MARTÍNEZ, Y. A. (2016): "La incidencia del artículo 32 de la Ley 40/2015 sobre la responsabilidad patrimonial del Estado-Legislador en materia tributaria, ¿crónica de una muerte anunciada?”, en Nueva Fiscalidad, núm. 5, pág. 168.

12 El citado art. 34 de la Ley 40/2015, refiriéndose a la indemnización, señala en el párrafo segundo de su apartado 1 que en los casos de responsabilidad patrimonial a los que se refiere los apartados 4 y 5 del art. 32 serán indemnizables los daños producidos en el plazo de los cinco años anteriores a la fecha de la publicación de la sentencia que declare la inconstitucionalidad de la norma con rango de ley o el carácter de norma contraria al Derecho de la Unión Europea, salvo que la sentencia disponga otra cosa. 
con carácter excepcional, la interpretación que en el ejercicio de su competencia lleva a cabo el Tribunal de Justicia tenga efectos ex tunc, a diferencia de lo que se deriva de la jurisprudencia del TJUE, a la luz de la cual el incumplimiento por parte de un Estado Miembro tiene efectos ex tunc, si bien excepcionalmente el Tribunal de Justicia podrá limitar los efectos temporales de sus sentencias ${ }^{13}$.

El número $5 .^{\circ}$ del citado precepto establece por su parte los requisitos exigidos para que el particular pueda acceder a la indemnización cuando el daño se origine de la declaración de vulneración del Derecho de la Unión Europea. Al margen de que se haya obtenido, en cualquier instancia, sentencia firme desestimatoria de un recurso contra la actuación administrativa que ocasionó el daño, siempre que se hubiera alegado la inconstitucionalidad posteriormente declarada, se requiere que la norma en cuestión tenga por objeto conferir derechos a los particulares, así como la debida caracterización del incumplimiento y la existencia de una relación de causalidad directa entre el incumplimiento de la obligación impuesta a la Administración responsable por el Derecho de la Unión Europea y el daño sufrido por los particulares.

Así las cosas, siendo la lesión consecuencia de la aplicación de una norma declarada contraria al Derecho de la UE procederá su indemnización cuando el particular haya obtenido, en cualquier instancia, sentencia firme desestimatoria de un recurso contra la actuación administrativa que ocasionó el daño, siempre que se haya alegado la infracción del Derecho de la UE posteriormente declarada. No obstante también será necesario que la norma tenga por objeto conferir derechos a los particulares y que el incumplimiento esté suficientemente caracterizado. Además, ha de existir una relación de causalidad directa entre el incumplimiento de la obligación impuesta a la Administración responsable por el Derecho de la UE y el daño sufrido.

Adviértase por tanto que, mientras que tratándose de una responsabilidad originada por la aplicación de normas declaradas vulneradoras del Derecho de la UE se exige el cumplimiento de los requisitos planteados por el TJUE para la declaración de vulneración del Derecho de la UE, hallándose el origen de dicha responsabilidad en la inconstitucionalidad de las mismas no se determinan qué requisitos han de ser aplicados, entendiendo con ello que serán los propios del ordenamiento jurídico interno. Tal y como apunta CAMPOS MARTÍNEZ ${ }^{14}$ "El artículo 32 en su numerales 4 y 5 , establece, para los dos supuestos de responsabilidad originada en la ilegalidad de la norma, el sometimiento como requisito previo a la acción, la obtención por parte del particular, en cualquier instancia, de sentencia firme desestimatoria de un recurso contra la actuación administrativa que ocasionó el daño, en donde se hubiera alegado la inconstitucionalidad o vulneración del Derecho de la UE posteriormente declarada. Lo que puede llegar a ser considerado como un límite restrictivo a la acción de responsabilidad patrimonial del Estado-Legislador desarrollada por el Tribunal Supremo, que va a impedir la consecución del restablecimiento de las situaciones perjudiciales y la tutela judicial efectiva, como fin último de esta institución».

Al amparo de lo establecido por el apartado quinto de este art. 32 de la Ley 40/2015 «Si la lesión es consecuencia de la aplicación de una norma declarada contraria al Derecho de la Unión Europea, procederá su indemnización cuando el particular haya obtenido, en cualquier instancia, sentencia firme desestimatoria de un recurso contra la actuación administrativa que ocasionó el daño, siempre que se hubiera alegado la infracción del Derecho de la Unión Europea posteriormente declarada. Asimismo, deberán cumplirse todos los requisitos siguientes:

a) La norma ha de tener por objeto conferir derechos a los particulares.

b) El incumplimiento ha de estar suficientemente caracterizado.

13 En palabras de MERINO JARA, I. (2018): “Editorial”, en Nueva Fiscalidad, núm. 2, pág. 14, «Lo que es regla, según la jurisprudencia comunitaria, se convierte en la normativa interna en excepción».

${ }^{14}$ CAMPOS MARTÍNEZ, Y. A. (2016): "La incidencia del artículo 32 de la Ley 40/2015 sobre la responsabilidad patrimonial del Estado-Legislador en materia tributaria, ¿crónica de una muerte anunciada?", ob. cit., pág. 170. Opina asimismo este autor en su trabajo "La responsabilidad patrimonial del Estado-Legislador por la recuperación de las ayudas de estado declaradas ilegales e incompatibles con el Derecho de la Unión Europea" (2017), Quincena Fiscal, núm. 13 (consultado en www.aranzadidigital.es), refiriéndose al alcance de este art. 32 de la Ley 40/2015, que "esta figura no presenta un desarrollo legislativo afianzado, ya que su nacimiento, evolución y consolidación lo debiamos a la jurisprudencia del Tribunal Supremo que, a través de sus decisiones y con las deficiencias propias del desarrollo pretoriano de la acción, había soportado y consolidado dicha responsabilidad con fundamento en una serie de principios generales del Derecho, principios constitucionales y principios del Derecho de la Unión Europea, desde los cuales entendía la necesidad de establecer una vía que permita resarcir los perjuicios ocasionados por la aplicación y promulgación de normas que generen una carga que los particulares no tienen la obligación de soportar, y que considerábamos válidos»; añade este autor en otra parte de su último trabajo que «Desafortunadamente los diversos intentos que propendían por la necesaria integración de la figura dentro del ordenamiento nacional han dejado entrever un interés más orientado a restringir su alcance que a desarrollar una regulación que permita el restablecimiento de las situaciones perjudiciales originadas de la declaración de antijuridicidad, ilegalidad o ilegitimidad de las normas tributarias, dentro de un sistema que propende a la distribución justa de las cargas públicas». 
c) Ha de existir una relación de causalidad directa entre el incumplimiento de la obligación impuesta a la Administración responsable por el Derecho de la Unión Europea y el daño sufrido por los particulares».

Por último, de acuerdo con lo dispuesto por el número $6 .^{\circ}$ del art. 32 de la Ley 40/2015 las decisiones del Tribunal Constitucional que declare la inconstitucionalidad de las normas internas, al igual que las decisiones del TJUE, producirá efectos desde la fecha de su publicación en el Boletín Oficial del Estado o, en su caso, en el Diario Oficial de la Unión Europea, según el caso, salvo que en ella se establezca otra cosa. Los efectos desde la publicación se producen tanto hacia adelante (eficacia prospectiva) como hacia atrás (eficacia retrospectiva), no siendo éstos condicionados.

Por su parte la Disposición Transitoria Quinta de la Ley 39/2015, de 1 de octubre, del Procedimiento Administrativo Común de las Administraciones Públicas, relativa a los procedimientos de responsabilidad patrimonial derivados de la declaración de inconstitucionalidad de una norma o su carácter contrario al Derecho de la Unión Europea, establece que aquellos procedimientos administrativos de responsabilidad patrimonial derivados de la declaración de inconstitucionalidad de una norma o su carácter contrario al Derecho de la Unión Europea que resulten iniciados con anterioridad a la entrada en vigor de la Ley 39/2015 se resolverán de acuerdo con la normativa vigente en el momento de su iniciación.

Adviértase por tanto que, al amparo de la citada reforma, la responsabilidad del Estado legislador solo podrá surgir cuando que el particular haya obtenido, en cualquier instancia, sentencia firme desestimatoria de un recurso contra la actuación administrativa que ocasionó el daño, siempre que se hubiera alegado la inconstitucionalidad posteriormente declarada. Se limita así la posible exigencia de responsabilidad a los supuestos en los que el obligado tributario, habiendo cumplido con la obligación de pago de un tributo posteriormente declarado inconstitucional con anterioridad a dicha declaración, hubiera actuado bien solicitando la nulidad de la liquidación bien la rectificación de la autoliquidación antes de la prescripción y, ante la denegación, hubiera acudido a los órganos jurisdiccionales y solicitado el planteamiento de una cuestión de inconstitucionalidad que hubiese sido rechazada.

Tal como ha precisado a este respecto CALATAYUD PRATS ${ }^{15}$, mientras que durante la vigencia de la anterior regulación la jurisprudencia del Tribunal Supremo admitía que los obligados tributarios solicitaran y obtuvieran el reintegro de las cantidades pagadas como consecuencia de la aplicación de un tributo declarado inconstitucional en aquellos supuestos en los que existiera una sentencia firme, un acto firme o una obligación prescrita mediante el ejercicio de una acción de responsabilidad, la reforma introducida por la Ley 40/2015 ha limitado dicha posibilidad a aquellos supuestos en los que el obligado hubiera tratado de impedir el pago del tributo mediante la impugnación de la liquidación ante los tribunales y solicitando el planteamiento de una cuestión de inconstitucionalidad, sin lograrlo. A tal efecto resultará exigible que quien solicite la indemnización haya obtenido, en cualquier instancia, sentencia firme desestimatoria de un recurso contra la actuación administrativa que ocasionó el daño, siempre que se hubiera alegado la inconstitucionalidad o infracción del Derecho de la Unión Europea. De este modo, siendo invocado un perjuicio derivado de la aplicación de una norma reaccionando contra dicha aplicación mediante la interposición de los correspondientes recursos resultará exigible la interposición de recurso contencioso-administrativo y que éste haya sido desestimado.

El art. 32 de la Ley 40/2015 no sólo se limita a establecer un requisito de procedibilidad similar al aplicado por la Administración Tributaria o el Consejo de Estado, sino que de igual manera plantea un trato diferenciado a los dos supuestos de responsabilidad del Estado-Legislador por normas declaradas antijurídicas o ilegítimas, cuando ya el TJUE y el Tribunal Supremo se han encargado de poner de manifiesto que son acciones de similar naturaleza que requieren de un trato equivalente.

En suma el art. 32 de la Ley 40/2015 (vigente con efectos desde el 2 de octubre de $2016{ }^{16}$ ) establece que la responsabilidad del Estado legislador podrá surgir tanto en aquellos supuestos en los que el daño

15 CALATAYUD PRATS, I. (2016): “La responsabilidad del estado legislador tributario”, en Quincena Fiscal, núm. 12 (consultado en www.aranzadidigital.es). En opinión de este autor "En el caso de aquellos sujetos que dejaran que su derecho a la rectificación prescribiera o que permitieran que el acto deviniera firme, por no recurrirlo o no acudir a los tribunales, se entiende que, en ningún caso, podrán solicitar la responsabilidad patrimonial del Estado legislador. Ello sin perjuicio claro está de aquellos supuestos en los no haya transcurrido más de cuatro años desde la presentación de la autoliquidación hasta la declaración de inconstitucionalidad del tributo autoliquidado, pues en estos supuestos, y salvo que la Sentencia del Tribunal Constitucional lo limite, será siempre posible solicitar la rectificación de la autoliquidación».

16 Como es sabido este artículo derogó el art. 139.3 de la antigua Ley 30/1992, de 26 de noviembre, de Régimen Jurídico de las Administraciones Públicas y del Procedimiento Administrativo Común, en virtud del cual «Las Administraciones Públicas indemnizarán a 
ocasionado derive de la aplicación de una norma con rango de ley declarada inconstitucional como cuando aquel proceda de la aplicación de una norma contraria al ordenamiento comunitario. Con carácter adicional prevé el citado precepto tanto si la lesión producida resulta ser consecuencia de la aplicación de una norma con rango de ley declarada inconstitucional como si se origina a resultas de la aplicación de una norma contraria al Derecho de la Unión Europea solo procederá la obtención de indemnización cuando el particular haya obtenido sentencia firme desestimatoria del recurso interpuesto contra la actuación administrativa que hubiese originado el daño, habiéndose argumentado a tal efecto la inconstitucionalidad o la infracción del ordenamiento comunitario declarada al efecto.

\section{A MODO DE CONCLUSIÓN}

La Ley 40/2015 exige, de cara al nacimiento de la posibilidad de ejercitar una acción de responsabilidad por ley declarada inconstitucional, que el obligado hubiera tratado de impedir el pago del tributo mediante la impugnación de la liquidación ante los tribunales solicitando el planteamiento de una cuestión de inconstitucionalidad a tal efecto sin logarlo. $Y$ se requiere como requisito para poder exigir responsabilidad por ley contraria a Derecho Comunitario que el particular haya obtenido, en cualquier instancia, sentencia firme desestimatoria de un recurso contra la actuación administrativa que ocasionó el daño, siempre que se hubiera alegado la infracción del Derecho de la Unión Europea posteriormente declarada. Con carácter adicional será necesario el cumplimiento de los siguientes requisitos: la norma ha de tener por objeto conferir derechos a los particulares; el incumplimiento ha de estar suficientemente caracterizado; y debe existir una relación de causalidad directa entre el incumplimiento de la obligación impuesta a la Administración responsable por el Derecho de la Unión Europea y el daño sufrido por los particulares.

No será posible por tanto el ejercicio de una acción de responsabilidad por ley contraria a Derecho Comunitario en caso de que existiera una sentencia firme desestimatoria en la que, sin embargo, no se hubiera alegado la infracción del citado ordenamiento en caso de que la liquidación sea firme (equivalente a la cosa juzgada), o bien en caso de que la obligación estuviera prescrita. Debe pues haberse invocado, con carácter previo a la declaración de responsabilidad, el posible quebrantamiento de los derechos y libertades comunitarias en la vía judicial precedente.

En todo caso las exigencias requeridas para que nazca la responsabilidad del Estado Legislador por infracción del Derecho Comunitario son equivalentes a las exigidas para que quepa la responsabilidad por leyes declaradas inconstitucionales. Ahora bien sin perjuicio de lo anterior creemos que debe reflexionarse acerca de si exigir que el obligado tributario haya recurrido en vía jurisdiccional y que, además, haya alegado la infracción del Derecho de la Unión Europea podría llegar a considerarse un requisito que hace imposible o excesivamente difícil el derecho del ciudadano ${ }^{17}$. Y ello teniendo presente que, con carácter general, la jurisprudencia comunitaria tiene declarado que para obtener la devolución de las cantidades ingresadas en aplicación de tributarios contrarios a Derecho Comunitario es necesario acudir a los requisitos materiales y formales fijados por las diferentes legislaciones nacionales, los cuales no pueden ser menos favorables que los exigidos a las reclamaciones similares de naturaleza interna ni quedar configurados de manera tal que hagan prácticamente imposible o excesivamente difícil el ejercicio de los derechos conferidos por el ordenamiento jurídico comunitario.

En este sentido fecha 19 de junio de 2017 se conoció que la Comisión Europea había abierto expediente contra el Reino de España por las medidas legales adoptadas para restringir y dificultar las posibilidades de reclamar una indemnización al Estado cuando la Administración infringe el Derecho Comunitario. A través de una carta de emplazamiento de fecha 14 de junio de 2017 la Comisión Europea advertía al Gobierno español de los daños que, sobre los derechos ciudadanos, producía la regulación introducida, señalando que «Las normas españolas en materia de responsabilidad del Estado por infracción del Derecho de la UE establecidas por el legislador español son contrarias a los principios de equivalencia y/o efectividad».

En opinión de la Comisión la regulación establecida en el art. 32 de la Ley 40/2015 determina que resulte excesivamente difícil comprometer la responsabilidad del Estado por una infracción de la legislación

\footnotetext{
los particulares por la aplicación de actos legislativos de naturaleza no expropiatoria de derechos y que éstos no tengan el deber jurídico de soportar, cuando asi se establezcan en los propios actos legislativos y en los términos que especifiquen dichos actos».

17 Véase en este sentido CALATAYUD PRATS, I. (2016): "La responsabilidad del estado legislador tributario", ob. cit., (consultado en www.aranzadidigital.es).
} 
de la UE, habiéndose establecido unas condiciones más duras para reclamar a raíz de una infracción de la legislación europea que cuando se trata de una infracción de la legislación española. Y ello en tanto en cuanto cuando los daños deriven de la aplicación de una norma con rango de ley declarada inconstitucional se requiere que concurran los requisitos del apartado 4 del art. 32.4 de dicha Ley, entre los cuales no se pide cualificación especial alguna de la inconstitucionalidad de la norma, lo que podría resultar contrario al principio de equivalencia. A mayor abundamiento la citada regulación interna limitaría de antemano el alcance las Sentencias del TJUE.

A tenor de lo declarado por la Comisión las actuales disposiciones nacionales sobre el régimen jurídico y sobre los procedimientos administrativos comunes para el Sector público limitan la autonomía procesal y material de los Estados miembros en relación con las condiciones que rigen las indemnizaciones por daños causados por actos legislativos, habiéndose establecido unas condiciones menos favorables en lo relativo a la responsabilidad por una infracción de la legislación de la UE que por la responsabilidad debida a una infracción de la Constitución e introduciéndose condiciones de procedimiento que no son acordes con la jurisprudencia consolidada del Tribunal de Justicia de la UE, haciendo que resulte excesivamente difícil comprometer la responsabilidad del Estado por una infracción de la legislación de la UE, lo que tiene una repercusión negativa en la efectividad del Derecho de la UE.

Tal y como hemos tenido ocasión de analizar de cara a poder solicitar una indemnización tras un fallo del TJUE la norma española aprobada exige haber reclamado y ganado con anterioridad ante un tribunal nacional, fijando además un plazo para reclamar de un año a partir de la sentencia del Tribunal europeo, de manera que los damnificados más recientes tal vez ni siquiera habrían tenido tiempo de defenderse a nivel nacional. Así las cosas atendiendo a la citada regulación podría resultar indefensa gran parte de la población perjudicada por una norma ilegal, salvo que hubiesen recurrido de manera previa para protegerse.

No obstante el principio de equivalencia se respetaría al establecerse como condición en el art. 32.5 de la Ley 40/2015 que el particular haya obtenido, en cualquier instancia, sentencia firme desestimatoria de un recurso contra la actuación administrativa que ocasionó el daño, siempre que se hubiera alegado la infracción del Derecho de la Unión Europea posteriormente declarada. Dichas condiciones resultan similares a las previstas para el supuesto de que la lesión sea consecuencia de la aplicación de una norma con rango de ley declarada constitucional (art. 32.4 de la Ley antes referida). Ahora bien tal y como ha señalado MERINO JARA $^{18}$ exigir el agotamiento previo de las vías de recurso discutida en el litigio principal podría no respetar el principio de efectividad.

De cualquier manera a resultas de la apertura del citado expediente la Comisión concedió al Reino de España un plazo de dos meses para efectuar alegaciones. El Ejecutivo español disponía así de un plazo de dos meses para presentar sus observaciones sobre el incumplimiento denunciado. En caso de no facilitar respuesta alguna o de que ésta fuese insatisfactoria la Comisión podría emitir un dictamen motivado, paso previo a la presentación de un recurso contra España ante el TJUE en caso de no modificarse la legislación española para adaptarse a los principios comunitarios. En definitiva, si el conflicto se mantuviese la Comisión podría presentar una denuncia ante el Tribunal de Justicia de Luxemburgo.

18 MERINO JARA, I. (2018): "Editorial”, ob. cit., pág. 13. Precisa no obstante este autor que «(...) Se respetaría el principio de equivalencia pese a requerirse una previa sentencia del Tribunal de Justicia que declare el carácter de norma contraria al Derecho de la Unión Europea de la ley nacional, puesto que también se exige una sentencia del Tribunal Constitucional que declare la inconstitucionalidad de la norma con rango de ley». En todo caso, a su juicio, no es descartable que el propio Tribunal Supremo acabe planteando cuestión prejudicial si llega a la conclusión de que algunos de los aspectos de la nueva regulación no son compatibles con el Derecho de la Unión Europea. 